\title{
ANALISIS KUALITAS PELAYANAN RUSUNAWA GUNUNG SARI SURABAYA
}

\author{
Niken Wulandari Purwaningdyah ${ }^{\text {a }}$, Ria. A. A. Soemitro ${ }^{\text {b }}$, dan Hitapriya Suprayitno ${ }^{c}$
}

\begin{abstract}
The paper disccuses an analysis study on the service quality of Rusunawa Gunungsari in terms of occupants satisfacion, condition of current management body of rusunawa, and management recommendation to improve the service quality of Rusunawa Gunungsari. The analysis is performed by using Importance Performance Analysis (IPA) for occupants satisfaction and 7s Mc Kinsey model as a framework to identify the current condition of management body of Rusunawa Gunungsari, then the results of these two analysis are used as inputs for management improvement recommendation. The results shows that the comparison between perception and expectation of occupant (Total Compliance Level) for Rusunawa Gunung Sari is equal to $74.18 \%$, the absence of maintenance regulation or Standard Operating Procedure (SOP), lack of occupant rules enforcement, insufficient rusunawa management budget, and lack of cleaners are management conditions that contribute to management low performance.The recommendation for improving management performance based on two analysis before are the management body should compile and implement the Standard Operating Procedure of rusunawa maintenance,enforce the occupants rules, add numbers of cleaners, and conduct an management evaluation as a maintenance budget reference.
\end{abstract}

Keywords: IPA,occupants satisfaction, rusunawa management, 7s Mc Kinsey Model, Rusunawa Gunungsari

\begin{abstract}
Abstrak: Makalah ini menyajikan hasil analisis kualitas pelayanan Rusunawa Gunungsari ditinjau dari kepuasan penghuni Rusunawa Gunungsari, kondisi organisasi badan pengelola saat ini, dan rekomendasi pengelolaan untuk meningkatkan kualitas pelayanan rusunawa Gunungsari. Analisis IPA digunakan untuk mengukur kepuasan penghuni rusunawa, sedangkan kerangka kerja model 7s McKinsey digunakan untuk menganalisis kondisi organisasi pengelola saat ini, hasil dari kedua analisis ini kemudian digunakan sebagai bahan untuk menentukan strategi pengelolaan di masa mendatang. Hasil akhir penelitian ini adalah perbandingan antara persepsi dan harapan penghuni (tingkat kesesuaian total) Rusunawa Gunung Sari adalah sebesar $74.18 \%$. Tidak adanya kebijakan pengelola terkait dengan pemeliharaan dan perawatan rusunawa, kurangnya penegakan tata tertib penghuni dan kurangnya jumlah tenaga kebersihan merupakan kondisi organisasi yang berkontribusi terhadap kinerja pengelola di kuadran I. Berdasarkan hasil analisis kepuasan penghuni dan analisis organisasi, rekomendasi pengelolaan yang dapat dilakukan oleh pengelola dimasa mendatang untuk meningktkan kinerja pelayanan Rusunawa Gunungsari yang berada di kuadran I yaitu pengelola perlu menyusun dan melaksanakan SOP pemeliharaan dan perawatan rusunawa, menegakkan tata tertib hunian dengan baik, melakukan evaluasi pengelolaan rusunawa secara menyeluruh sehingga dapat dijadikan dasar penganggaran tahun berikutnya terutama untuk perawatan dan pemeliharaan, dan menambah jumlah tenaga kebersihan.
\end{abstract}

Kata Kunci: IPA, kepuasan penghuni,pengelolaan rusunawa, model 7s McKinsey, Rusunawa Gunungsari

\section{PENDAHULUAN}

Pembangunan perumahan di perkotaan selalu menghadapi persoalan kecenderungan meningkatnya perintaan dan kurangnya penyediaan pasar di perumahan, sehingga munculah backlog perumahan, yang berakibat tingginya harga rumah. Pemerintah Indonesia lebih memberlakukan rumah sebagai barang atau kebutuhan sosial. Hal ini dapat dilihat dari besarnya peran pemerintah dalam membantu pemenuhan kebutuhan perumahan yang layak bagi masyarakat, khususnya masyarakat berpenghasilan rendah, dengan melaksanakan pembangunan rumah susun di kota besar. Konsep pembangunan rumah susun pada hakekatnya

aPersonnel at Dinas Perumahan Rakyat Kawasan Permukiman dan Cipta Karya Provinsi Jawa Timur and a student in the Department of Civil Engineering, Sepuluh Nopember Institute of Technology (ITS), ITS Campus, Sukolilo, Surabaya 60111, Indonesia. Email: niken.wp@gmail.com

${ }^{b, c}$ Lecturer in the Department of Civil Engineering, Sepuluh Nopember Institute of Technology (ITS), ITS Campus, Sukolilo, Surabaya 60111, Indonesia. Email: ria@ce.its.ac.id; suprayitno.hita@gmail.com

Note. The manuscript for this paper was submitted for review and possible publication on January 09, 2018. This paper is part of the ITS Journal of Civil Engineering, Vol. 33, No. 2, November 2018. (C) ITS Journal of Civil Engineering, ISSN 2579-9029/2017. dimaksudkan untuk mengatasi masalah kualitas lingkungan yang semakin menurun maupun untuk mengatasi keterbatasan lahan dalam kota . Akan tetapi dalam perkembangannya banyak rusunawa yang telah dihuni tidak dikelola dengan baik, akibatnya kondisi rusunawa menjadi kumuh dan tidak terawat, hal ini justru bertentangan dengan tujuan didirikannya rusunawa. Pengelolaan rusunawa yang efektif mempunyai peranan penting dalam keberlangsungan rusunawa, agar permasalahan kebutuhan perumahan dan permukiman yang sehat dan nyaman dapat diatasi.

Tujuan penelitian ini adalah untuk menganalisis kualitas pelayanan Rusunawa Gunung Sari berdasarkan persepsi dan harapan penghuni dan menganalisis kondisi organisasi pengelola Rusunawa Gunung Sari serta memperoleh rekomendasi strategi pengelolaan yang dapat dilakukan oleh pengelola dimasa mendatang.

Pengelolaan Rusunawa adalah upaya terpadu yang dilakukan oleh badan pengelola atas barang milik negara/daerah yang berupa rusunawa dengan melestarikan fungsi rusunawa yang meliputi kebijakan perencanaan, pengadaan, penggunaan, pemanfaatan, pengamanan dan pemeliharaan, penilaian, penghapusan, pemindahtanganan, penatausahaan, pembinaan, pengawasan, dan pengendalian rusunawa. Sedangkan ruang lingkup pengelolaannya meliputi pemanfaatan fisik, 
kepenghunian, administrasi keuangan dan pemasaran, kelembagaan, penghapusan dan pengembangan bangunan rusunawa, pendampingan, monitoring, dan evaluasi.[9]

Sesuai dengan amanat Undang-Undang [7], maka diperlukan sebuah organisasi atau badan yang mengelola rusunawa. Badan pengelola tersebut memiliki tugas melakukan pengelolaan rusunawa untuk menciptakan kenyamanan dan kelayakan hunian dan bukan hunian serta kelangsungan umur bangunan rusunawa. Secara umum model organisasi unit pengelola lokasi rusunawa dibedakan dalam 2 model, yaitu :

- Model swakelola yaitu pengelola operasional merupakan bagian dari organisasi pemilik atau yang mewakili pemilik rusunawa, yaitu unit pelaksana teknis (UPT) atau badan usaha milik negara/daerah (BUMN/BUMD) atau perhimpunan penghuni/pemilik rusunawa atau perusahaan swasta pengembang rusunawa.

- Model kemitraan atau kerja sama operasional yaitu pengelolaan operasional yang dilakukan oleh pihak ketiga, terdiri dari konsultan properti, koperasi dan perhimpunan penghuni, yang bermitra dengan pemilik/yang mewakili pemilik/pemegang hak pengelolaan rusunawa untuk melakukan tugas pengelolaan operasional rusunawa dalam jangka waktu yang ditentukan dan sesaui dengan peraturan yang berlaku.

Sesuai dengan Surat Edaran Menteri Pekerjaan Umum No. 7/2013 pengelola rusunawa harus mempunyai kompetensi pada aspek kelembagaan, manajemen keuangan, pemeliharaan, perawatan, serta pencegahan dan penanggulangan bahaya,aspek legal, penghunian, pengembangan komunitas, dan manjemen konflik.

Sedangkan pola pengelolaan rusunawa tergantung dari pola investasi yang diterapkan, yaitu terdiri dari :

a) Pola Unit Pelaksana Teknis (UPT)

Investasi yang dilakukan oleh pemerintah melalui APBD/APBN yang tidak mengharapkan pengembalian investasi, tanah bangunan serta fasilitas dilakukan diatasnya dikelola oleh UPT. Unit Pelaksana Teknis merupakan unit yang dibentuk setelah seluruh proses pembangunan selesai, hingga serah terima rusun diselesaikan.

b) Pola Penyertaan Modal Negara/Pemerintah (PMN) Jenis investasi ini biasanya dilakukan bersama dengan BUMN/BUMD. Penyertaan modal pemerintah/negara yang diharapkan pulih biaya untuk digulirkan ke lokasi lain tanpa memperhitungkan tingkat keuntungan dari nilai investasi tersebut. Penyertaan modal pemerintah kepada BUMN/BUMD sehingga BUMN/BUMD memiliki wewenang dapat mengelola asset tanah dan bangunan tersebut.

c) Pola Kemitraan

Investasi dilakukan oleh usaha bersama dalam bentuk kerja sama pembiayaan dan pengelolaan rusunawa antara perorangan atau kelompok masyarakat berbadan hukum (koperasi, yayasan, asosiasi profesi, dll) dan atau perusahaan dengan para investor atau kreditur yang difasilitasi oleh pemerintah. Pola ini diharapkan pulih biaya baik untuk biaya pengelolaan maupun biaya investasi serta keuntungan tertentu yang diharapkan dari nilai investasi yang ditanamkan. Pengelolaan dilakukan secara professional oleh badan pengelola dengan memperhatikan kaidah manajemen properti.

Kepuasan pelanggan menurut Berry [1] adalah perasaan pelanggan terhadap satu jenis pelayanan yang didapatkannya. Schiffman dan Kanuk [2] menandaskan bahwa kepuasan pelanggan merupakan perasaan seseorang terhadap kinerja dari suatu produk atau jasa yang dibandingkan dengan harapannya. Sedangkan pendekatan konsep kepuasan penghuni melibatkan 4 sub sistem yang saling berinteraksi, yaitu sub sistem penghuni, hunian, lingkungan, dan pengelolaan (manajemen).[3].

Varady dan Carrozza [4] berpendapat bahwa secara kualitatif kepuasan tinggal di rusun sewa didefinisikan seberapa baik rusun memenuhi harapan responden. sedangkan secara kuantitatif, kepuasan tinggal di rusun sewa didefinisikan sebagai suatu kondisi terpenuhinya berbagai faktor yang menjadi harapan penghuni. Berbagai faktor tersebut, bisa berasal dari lingkungan eksternal atau internal atau gabungan keduanya, menentukan tingkat kepuasan tinggal di rusun sewa. Penghuni rusun (public housing) memiliki tingkat kepuasan yang tinggi apabila tinggal di rusun yang dilengkapi dengan berbagai karakteristik rusun (fisik dan non-fisik) yang berkualitas, seperti kualitas bangunan yang baik; memiliki sarana \& prasarana yang lengkap dan terpelihara; komunikasi yang terjalin baik antara penghuni dengan badan pengelola. Secara spesifik berbagai karakteristik melekat yang ditemui pada rusun dan mempengaruhi kepuasan penghuni diantaranya adalah (a) tarif sewa, (b) kualitas layanan oleh badan pengelola, (c) kualitas bangunan, (d) kelengkapan sarana \& prasarana, (e) pengelolaan rusun oleh manajemen pengelola dan (f) kualitas lokasi.[5] Kepuasan penghuni rusunawa dapat dianalisis menggunakan analisis kuadran atau Importance Performance Analysis untuk mengidentifikasi faktorfaktor kinerja penting apa yang harus ditunjukkan oleh suatu organisasi dalam memenuhi kepuasan para pengguna jasa mereka (konsumen) [10]. IPA mempunyai fungsi utama untuk menampilkan informasi berkaitan dengan faktor-faktor pelayanan yang menurut konsumen sangat mempengaruhi kepuasan dan loyalitas mereka, dan faktor-faktor pelayanan yang menurut konsumen perlu ditingkatkan karena kondisi saat ini belum memuaskan.

Untuk menganalisis organisasi dan efektifitas organisasi, salah satu metode yang dapat digunakan adalah menggunakan McKinsey 7s Framework atau Kerangka Kerja 7s McKinsey, dimana ketujuh elemen tersebut dalam organisasi merupakan faktor kunci keberhasilan sebuah perusahaan. Ketujuh Elemen yang dimaksud dalam McKinsey 7s ini memiliki hubungan yang saling berketergantungan satu sama lainnya. Perubahan pada satu elemen akan mempengaruhi elemen lainnya[6] Gruis [3] kemudian mengadaptasi Mc Kinsey 7s Framework untuk menganalisis organisasi pengelola rusunawa di Nigeria. Metode ini dapat menggambarkan organisasi secara menyeluruh dengan melibatkan elemenelemen yang terlibat. Elemen-elemen yang terdapat dalam '7s' model yang digunakan untuk menganalisis organisasi pengelolaan rusunawa antara lain : 
1. Strategi/kebijakan

Menjelaskan kebijakan yang digunakan oleh badan pengelola dalam mengelola rusunawa. Kebijakan ini dapat berasal dari kebijakan pemerintah pusat yang diadopsi oleh badan pengelola rusunawa maupun kebijakan badan pengelola sendiri untuk mengelola rusunawa.

2. Anggaran dan pembiayaan

Mengacu kepada bagaimana badan pengelola memperolah anggaran untuk membiayai pengelolaan rusunawa.

3. Sumber Daya Manusia

Menjelaskan kompetensi sumber daya manusia badan pengelola dalam pengelolaan rusunawa, baik secara teknis maupun manajemen.

4. Culture/Budaya

Mengacu kepada standar dan nilai badan pengelola dalam pengelolaan rusunawa, apakah badan pengelola berorientasi pada penghuni atau tidak.

5. Regulasi

Mengacu kepada peraturan dan perundangan dalam pengelolaan rusunawa serta mengatur hak dan kewajiban pengelola maupun penghuni.

6. Struktur Organisasi

Menjelaskan tentang tata kerja organisasi, tugas, tanggung jawab, dan koordinasi dari masing-masing fungsi bagian organisasi dan koordinasi antara pemangku kepentingan yang terlibat dalam pengelolaan rusunawa.

7. Kualitas Rusunawa

Mengacu pada kualitas fisik rusunawa dalam hal material, konstruksi bangunan, dan kualitas perawatan dan perbaikan yang dilakukan oleh badan pengelola.

\section{KEPENTINGAN RISET}

Pengukuran kepuasan penghuni rusunawa telah dilakukan para peneliti terdahulu dan menunjukkan bahwa faktor tarif sewa, manajemen badan pengelola, kualitas bangunan dan kelengkapan sarana prasarana rusunawa berpengaruh terhadap kepuasan penghuni rusunawa. Namun, penelitian evaluasi pengelolaan rusunawa yang memperhitungkan aspek kepuasan penghuni dan aspek manajemen pengelola masih perlu dilakukan. Penelitian ini dapat menjadi masukkan awal dalam penyusunan evaluasi pengelolaan rusunawa secara menyeluruh, baik secara fisik maupun organisasi.

\section{METODOLOGI}

Pada penelitian ini dilakukan analisis kepuasan penghuni Rusunawa Gunungsari menggunakan metode $I P A$, sedangkan analisis organisasi pengelola Rusunawa Gunungsari menggunakan kerangka kerja Model 7s McKinsey. Hasil kedua analisis tersebut digunakan sebagai bahan rekomendasi pengelolaan Rusunawa Gunungsari untuk meningkatkan kualitas yang pelayanan yang berada di kuadran I analisis IPA. Secara ringkas metodologi dalam penelitian ini digambarkan seperti pada Gambar 1.

\section{ANALISIS DAN PEMBAHASAN}

Profil Rusunawa Gunungsari ditunjukkan pada Tabel 1. Atribut kepuasan penghuni dalam penelitian ini diperoleh dari sintesa beberapa peraturan yang terkait rusun yang ada di Indonesia. Terdapat 29 atribut kepuasan penghuni yang setelah uji validitas dan reliabilitas dinyatakan valid dan reliabel untuk digunakan sebagai kuesioner. Kuesioner kepuasan penghuni disebarkan kepada 73 responden selaku sampel dari 268 KK yang ada di Rusunawa Gunung Sari,dan dianalisa menggunakan Importance Performance Analysis diperoleh hasil seperti yang ditunjukkan pada Tabel 2. Sedangkan hasil analisis IPA kepuasan penghuni Rusunawa Gunung Sari ditunjukkan pada Gambar 2.

Dari analisis IPA dapat diketahui bahwa atribut yang terletak di kuadran I atau kinerja pengelola yang perlu ditingkatkan dapat dilihat di Tabel 3.

Rusunawa Gunung Sari adalah aset milik Pemerintah Provinsi Jawa Timur [8] yang dikelola oleh Dinas Perumahan, Kawasan Permukiman dan Cipta Karya Provinsi Jawa Timur. Dalam pelaksanaan tugas pengelolaan rusunawa ini Dinas bekerja sama dengan pihak ke tiga dengan sistem outsourcing (pengadaan jasa). Pihak ketiga ini bertindak selaku pengelola lokasi, yang tugasnya menerima biaya sewa unit rusunawa untuk selanjutnya disetorkan kepada bendahara Dinas yang kemudian disetorkan ke kas daerah, bertanggung jawab atas kebersihan lingkungan rusunawa, menjaga keamanan dan ketertiban di rusunawa serta keadministrasian penghuni.

Sesuai dengan kerangka kerja 7s Mc Kinsey, analisis organisasi pengelola Rusunawa Gunung Sari dapat dilihat seperti pada Tabel 4.

Varabel strategi/kebijakan berupa tidak adanya strategi/kebijakan terkait pemeliharaan dan perawatan rusunawa berkontribusi menghasilkan seluruh atribut kepuasan penghuni yang berada pada kuadran I. Variabel sistem/regulasi berupa tidak adanya SOP pemeliharaan dan perawatan rusunawa dan variabel anggaran/pembiayaan yaitu keterbatasan anggaran pemeliharaan dan perawatan menyebabkan atribut sarana pembuangan air lmbah/kotor, kualitas perbaikan sarana, prasarana, dan utilitas rusunawa, pekerjaan pemeliharaan dan pemeriksaan berkala pada komponen bangunan, dan pekerjaan perawatan bangunan berada pada kuadran I. Variabel sistem/regulasi berupa tidak adanya penegakan tata tertib penghuni terkait kebersihan menyebabkan atribut pengelolaan sampah berada pada kuadran I. Variabel anggaran/pembiayaan yaitu terbatasnya anggaran pengelolaan dan variabel SDM yaitu kurangnya jumlah SDM kebersihan berkontribusi menyebabkan atribut kecukupan SDM berada di kuadran I. Dengan memperhatikan analisis kepuasan penghuni dan analisis organisasi pada Rusunawa Gunungsari, maka rekomendasi pengelolaan Rusunawa Gunung Sari untuk meningkatkan kinerja pelayanan rusunawa yang berada pada kuadran I dimasa mendatang ditunjukkan pada Tabel 5. 


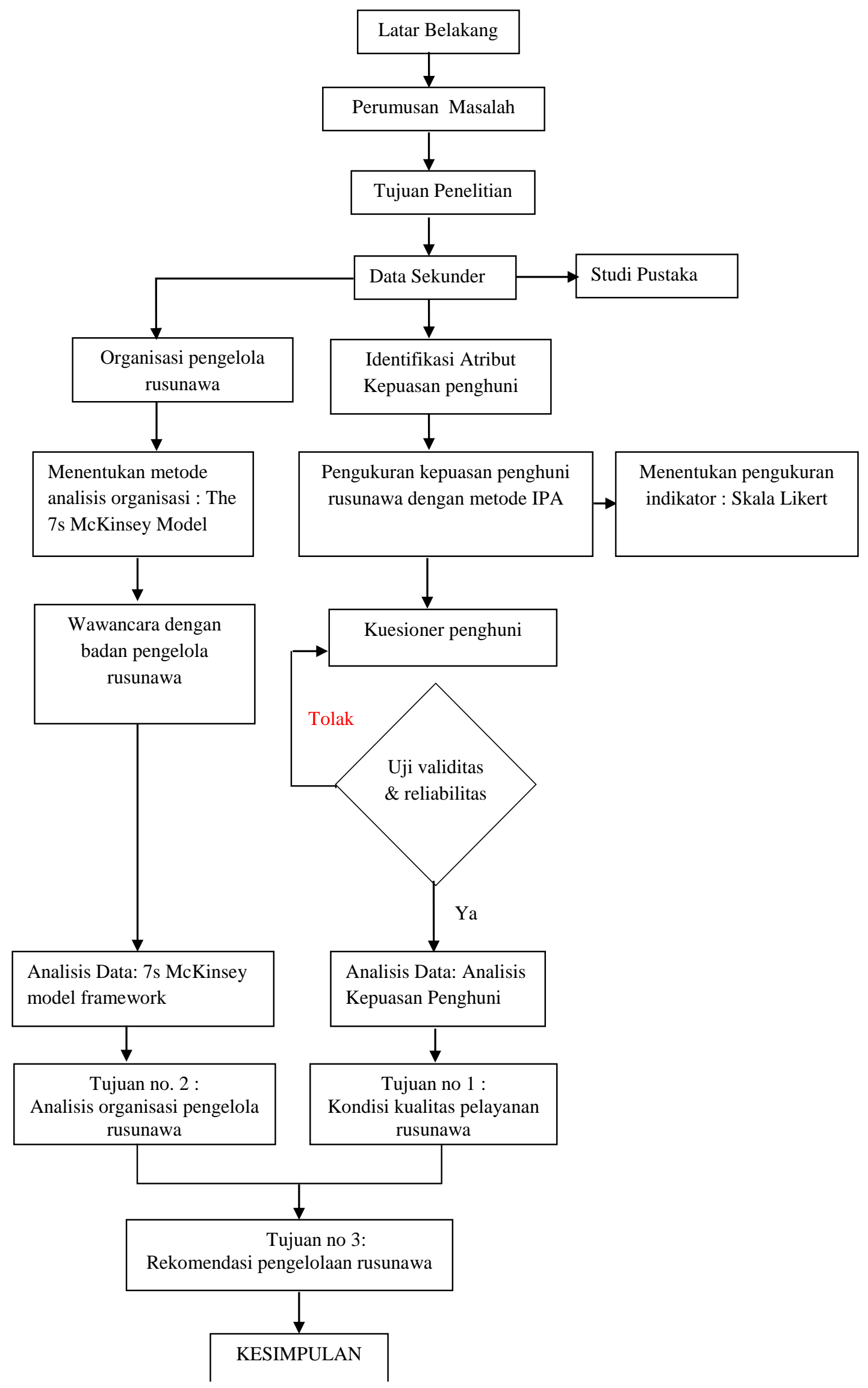

Gambar 1. Alur Penelitian 
Tabel 1. Profil Rusunawa Gunungsari

\begin{tabular}{|c|c|c|}
\hline Alamat & : & Jl. Gunung Sari, Kecamatan Wonokromo, Kota Surabaya \\
\hline Luas Lahan & : & $6.799 \mathrm{~m}^{2}$ \\
\hline $\begin{array}{l}\text { Jumlah twin blok } \\
\text { (TB) }\end{array}$ & : & $3 \mathrm{~TB}$, masing-masing TB terdiri dari 5 lantai \\
\hline Jumlah unit hunian & : & 268 unit, dengan luas per unitnya $34 \mathrm{~m}^{2}$ \\
\hline Fasilitas & $\cdot$ & Komersial, ibadah \\
\hline $\begin{array}{l}\text { Sumber dana } \\
\text { pembangunan }\end{array}$ & : & APBD Provinsi Jawa Timur 2010-2011 \\
\hline Pengelola & : & $\begin{array}{l}\text { Dinas Perumahan Kawasan Permukiman dan Cipta Karya Provinsi Jawa Timur } \\
\text { dengan menggandeng pihak ketiga sebagai pengelola di lokasi rusunawa. }\end{array}$ \\
\hline $\begin{array}{l}\text { Tarif sewa } \\
\text { hunian/bulan (tidak } \\
\text { termasuk listrik dan } \\
\text { air) }\end{array}$ & : & $\begin{array}{l}\text { Lantai } 1 \text { : Rp. } 235.000 \\
\text { Lantai } 2 \text { : Rp. } 215.000 \\
\text { Lantai } 3 \text { : Rp. } 195.000 \\
\text { Lantai } 4 \text { : Rp. } 175.000 \\
\text { Lantai } 5 \text { : Rp. } 156.000 \\
\text { Sewa unit komersial : Rp. } 700.000\end{array}$ \\
\hline Sasaran penghuni & & Warga eks stren Kali Jagir \\
\hline
\end{tabular}

Tabel 2. Kepuasan Penghuni Rusunawa Gunungsari

\begin{tabular}{lllll}
\hline No & Atribut & $\begin{array}{l}\text { Rata-rata } \\
\text { Persepsi } \\
\text { (x) }\end{array}$ & $\begin{array}{l}\text { Rata-rata } \\
\text { Harapan } \\
(\mathbf{y})\end{array}$ & $\begin{array}{l}\text { Tingkat } \\
\text { kesesuaian } \\
(\%)\end{array}$ \\
\hline Prasarana, sarana, dan utilitas & & & \\
\hline 1 & Ketersediaan air bersih & 4.08 & 4.58 & 89.22 \\
\hline 2 & Ketersediaan listrik & 3.92 & 4.63 & 84.62 \\
\hline 3 & Sarana pembuangan air limbah/kotor & 2.92 & 4.47 & 65.34 \\
\hline 4 & Fasilitas KM/WC & 3.67 & 4.25 & 86.45 \\
\hline 5 & Fasilitas dapur/memasak & 3.88 & 4.33 & 89.56 \\
\hline 6 & Fasilitas jemur pakaian & 2.63 & 4.29 & 61.34 \\
\hline 7 & Pengelolaan sampah & 3.12 & 4.33 & 72.15 \\
\hline
\end{tabular}


Lanjutan Tabel 2

\section{No Atribut}

Rata-rata

Persepsi

(x)

\section{Rata-rata Tingkat \\ Harapan kesesuaian \\ (y)}

\begin{tabular}{|c|c|c|c|c|}
\hline \multicolumn{5}{|c|}{ Prasarana, sarana, dan utilitas } \\
\hline 8 & Fasilitas parkir kendaraan penghuni & 3.51 & 4.42 & 79.26 \\
\hline 9 & $\begin{array}{l}\text { Fasilitas pemadam kebakaran (hydrant, sirine kebakaran, alat } \\
\text { pemadam) }\end{array}$ & 3.47 & 4.47 & 77.61 \\
\hline 10 & Fasilitas aula/tempat berkumpul & 3.88 & 4.22 & 91.88 \\
\hline 11 & Ketersediaan Unit sewa komersial & 2.88 & 3.55 & 81.08 \\
\hline 12 & Ketersediaan tempat beribadah/musholla & 3.51 & 4.45 & 78.77 \\
\hline \multicolumn{5}{|c|}{ Operasionalisasi dan pengelolaan bangunan rusunawa } \\
\hline 13 & Kualitas pekerjaan perbaikan sarana, prasarana, dan utilitas & 2.33 & 4.45 & 52.31 \\
\hline 14 & $\begin{array}{l}\text { Pekejaan pemeliharaan dan pemeriksaan berkala pada } \\
\text { komponen bangunan }\end{array}$ & 2.33 & 4.30 & 54.14 \\
\hline 15 & Pekerjaan perawatan bangunan & 2.33 & 4.25 & 54.84 \\
\hline 16 & $\begin{array}{l}\text { Perawatan lingkungan sekitar rusun (jalan lingkungan, taman, } \\
\text { penerangan) }\end{array}$ & 2.29 & 4.14 & 55.30 \\
\hline 17 & Tarif sewa hunian & 3.67 & 4.26 & 86.17 \\
\hline 18 & Tersedia tata tertib penghuni, dan sanksi atas pelanggaran & 3.16 & 4.03 & 78.57 \\
\hline 19 & Pelaksanaan tata tertib hunian & 3.16 & 4.08 & 77.52 \\
\hline 20 & Pelaksanaan sosialisasi pemasaran dan tata cara penghunian & 2.92 & 4.00 & 72.95 \\
\hline 21 & $\begin{array}{l}\text { Pelaksanaan sosialisasi hak, kewajiban, larangan, dan sanksi } \\
\text { penghuni }\end{array}$ & 3.08 & 3.88 & 79.51 \\
\hline 22 & Sosialisasi tata cara penyelamatan terhadap bencana kebakaran & 2.52 & 4.08 & 61.77 \\
\hline & Manajemen konflik oleh pengelola & 3.03 & 3.84 & 78.93 \\
\hline
\end{tabular}

\begin{tabular}{llccc}
\hline \multicolumn{2}{l}{ Kelembagaan } & & & \\
\multicolumn{2}{l}{ Kecukupan SDM pengelola } & 2.74 & 4.27 & 64.10 \\
\hline 25 & Kompetensi SDM pengelola & 2.99 & 4.16 & 71.71 \\
\hline 26 & Jam kerja pengelola & 3.42 & 4.05 & 84.46 \\
\hline 27 & Ketersediaan SOP/tata cara pengaduan penghuni & 3.22 & 4.14 & 77.81 \\
\hline 28 & Respon pengelola terhadap keluhan penghuni & 2.89 & 4.29 & 67.41 \\
\hline 29 & Usaha pengelola untuk mewujudkan keamanan dan ketertiban & 3.45 & 4.29 & 80.51 \\
\hline TINGKAT KESESUAIAN TOTAL & $\mathbf{7 4 . 1 8 \%}$ & & \\
\hline
\end{tabular}




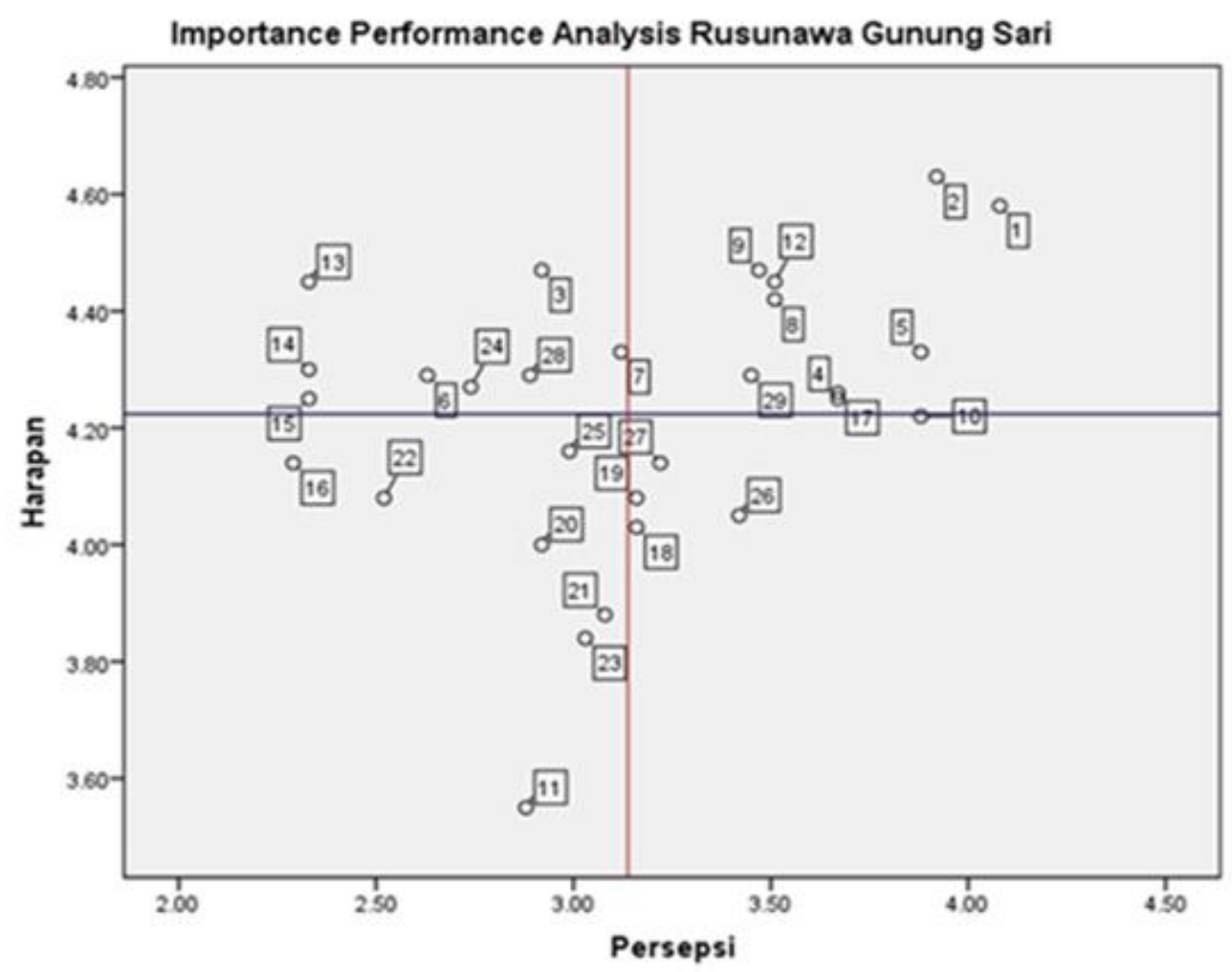

Gambar 2. Importance Performance Analysis Rusunawa Gunungsari

Tabel 3. Atribut Kepuasan Penghuni yang Berada di Kuadran I

\begin{abstract}
Sarana pembuangan air limbah/kotor
\end{abstract}

Fasilitas jemur pakaian
Pipa saluran limbah/air kotor tersumbat

Bak septitank penuh

Fasilitas jemur pakaian berada pada masing-masing unit hunian dan letaknya di atas dapur, tertutupi oleh teralis sehingga cahaya matahari yang masuk kurang
Pengelolaan sampah

- Pengangkutan sampah dari TPS ke TPA hanya 2 x seminggu

- Petugas kebersihan hanya berjumlah 2 orang

\begin{tabular}{ll}
\hline $\begin{array}{l}\text { Kualitas perbaikan sarana, } \\
\text { prasarana, dan utilitas }\end{array}$ & $\begin{array}{l}\text { Perbaikan kerusakan sering tidak maksimal, sehingga kerusakan yang sama } \\
\text { terjadi berulang }\end{array}$ \\
\hline $\begin{array}{l}\text { Pekerjaan pemeliharaan dan } \\
\text { pemeriksaan berkala pada } \\
\text { komponen bangunan }\end{array}$ & $\begin{array}{l}\text { Pemeriksaan berkala pada komponen bangunan jarang dilakukan, pengelola } \\
\text { lebih sering memperbaiki kerusakan. }\end{array}$
\end{tabular}

Pekerjaan perawatan bangunan $\quad$ Pekerjaan perawatan bangunan dilakukan secara minimal

Kecukupan SDM Pengelola

- Petugas kebersihan hanya 3 orang

- Tidak ada petugas teknis untuk perawatan dan pemeliharaan

\begin{tabular}{ll}
\hline Respon pengelola terhadap & $\begin{array}{l}\text { Pengelola hanya mencatat keluhan penghuni, biasanya masalah kerusakan } \\
\text { keluhan penghuni }\end{array}$ \\
& ditangani
\end{tabular}


Tabel 4. Analisis Organisasi Pengelola Rusunawa Gunungsari

\begin{tabular}{|c|c|c|c|c|}
\hline No & 7s Mc Kinsey & Hasil analisis & & \\
\hline \multirow[t]{6}{*}{1} & \multirow[t]{6}{*}{$\begin{array}{l}\text { Strategi/Kebija } \\
\text { kan }\end{array}$} & \multirow[t]{3}{*}{$\begin{array}{l}\text { Kebijakan } \\
\text { pengelolaan }\end{array}$} & $\begin{array}{l}\text { Kebijakan tarif } \\
\text { sewa }\end{array}$ & $\begin{array}{l}\text { Tarif sewa dasar dengan subsidi, tarif sewa } \\
\text { tidak lebih dari 1/3 UMR pada Tahun } 2011 \\
\text { (Tahun pertamakalinya Rusunawa beroperasi) }\end{array}$ \\
\hline & & & $\begin{array}{l}\text { Kebijakan } \\
\text { penghunian }\end{array}$ & $\begin{array}{l}\text { Sasaran penghuni adalah warga eks Kali Jagir } \\
\text { yang direlokasi, MBR }\end{array}$ \\
\hline & & & $\begin{array}{l}\text { Kebijakan } \\
\text { pemeliharaan/pera } \\
\text { watan }\end{array}$ & - $\quad$ Tidak ada \\
\hline & & \multirow[t]{3}{*}{$\begin{array}{l}\text { Implementasi } \\
\text { kebijakan }\end{array}$} & $\begin{array}{l}\text { Implementasi } \\
\text { kebijakan tarif sewa }\end{array}$ & $\begin{array}{l}\text { - Dengan tarif sewa yang telah ditetapkan } \\
\text { banyak penghuni yang menunggak membayar } \\
\text { sewa }\end{array}$ \\
\hline & & & $\begin{array}{l}\text { Implementasi } \\
\text { kebijakan } \\
\text { penghunian }\end{array}$ & $\begin{array}{l}\text { Banyak penghuni yang tidak tepat sasaran, } \\
\text { penghuni bukan warga eks Jagir dan non MBR }\end{array}$ \\
\hline & & & $\begin{array}{l}\text { Implementasi } \\
\text { kebijakan } \\
\text { pemeliharaam/peraw } \\
\text { atan }\end{array}$ & $\begin{array}{l}\text { - Pengelola lebih banyak memperbaiki } \\
\text { kerusakan daripada melakukan } \\
\text { pencegahan/pemeriksaan berkala pada } \\
\text { komponen bangunan. Perbaikan dilakukakn } \\
\text { bila sudah dianggarkan. }\end{array}$ \\
\hline \multirow[t]{7}{*}{2} & \multirow[t]{7}{*}{$\begin{array}{l}\text { Sistem/Re- } \\
\text { gulasi }\end{array}$} & \multirow[t]{7}{*}{$\begin{array}{l}\text { Pengelolaan } \\
\text { Rusunawa }\end{array}$} & Regulasi tarif sewa & $\begin{array}{l}\text { - } \quad \text { Peraturan Gubernur Provinsi Jawa Timur No. } \\
36 \text { Tahun } 2011 \text { Tentang Pedoman Pengelolaan } \\
\text { Rusunawa Provinsi Jawa Timur. }\end{array}$ \\
\hline & & & Regulasi Penghunian & $\begin{array}{l}\text { - } \quad \text { Peraturan Gubernur Provinsi Jawa Timur No. } \\
36 \text { Tahun } 2011 \text { Tentang Pedoman Pengelolaan } \\
\text { Rusunawa Provinsi Jawa Timur. }\end{array}$ \\
\hline & & & $\begin{array}{l}\text { Regulasi } \\
\text { pemeliharaan/perawa } \\
\text { tan }\end{array}$ & $\begin{array}{l}\text { - Peraturan Menteri Pekerjaan Umum No. } 24 \\
\text { Tahun } 2008\end{array}$ \\
\hline & & & $\begin{array}{l}\text { Implementasi sistem } \\
\text { tarif sewa hunian }\end{array}$ & $\begin{array}{l}\text { - } \text { Banyak penghuni yang menunggak biaya } \\
\text { sewa, dan tidak ada sanksi bagi penghuni yang } \\
\text { menunggak biaya sewa. }\end{array}$ \\
\hline & & & $\begin{array}{l}\text { Implementasi sistem } \\
\text { penghunian }\end{array}$ & $\begin{array}{l}\text { - Sasaran penghuni hanya berlaku pada saat } \\
\text { proses penghunian rusunawa di awal } \\
\text { beroperasinya, tetapi kontrol penghuni } \\
\text { rusunawa agar sesuai dengan sasaran penghuni } \\
\text { tidak dilakukan. }\end{array}$ \\
\hline & & & & $\begin{array}{l}\text { - } \text { Kontrol terhadap kepenghunian perlu } \\
\text { ditingkatkan karena masih ada alih sewa unit } \\
\text { hunian secara illegal }\end{array}$ \\
\hline & & & & $\begin{array}{l}\text { Penerapan tata tertib hunian belum baik, } \\
\text { walaupun telah ada tata tertib penghuni akan } \\
\text { tetapi sanksi tidak terapkan bila ada yang } \\
\text { melanggar }\end{array}$ \\
\hline
\end{tabular}




\section{Lanjutan Tabel 4}

\begin{tabular}{|c|c|c|}
\hline \multirow{3}{*}{$\begin{array}{l}\text { Implementasi sistem perawatan dan } \\
\text { pemeliharaan bangunan }\end{array}$} & - & Pemeliharaan berkala jarang dilakukan \\
\hline & - & $\begin{array}{l}\text { Perawatan/perbaikan komponen bangunan dilakukan } \\
\text { menunggu anggaran disediakan }\end{array}$ \\
\hline & - & $\begin{array}{l}\text { Tidak mempunyai SOP pemeliharaan dan perawatan } \\
\text { bangunan }\end{array}$ \\
\hline Evaluasi pengelolaan rusunawa & - & $\begin{array}{l}\text { Evaluasi pengelolaan rusunawa tidak dilakukan dengan } \\
\text { maksimal, hanya secara umum saja yang menyangkut } \\
\text { penghunian (jumlah penghuni) dan keuangan } \\
\text { (pendapatan sewa) }\end{array}$ \\
\hline \multirow[t]{2}{*}{ Bentuk Organisasi } & - & $\begin{array}{l}\text { Organisasi pengelola berada di bawah seksi pengendalian } \\
\text { dan pengembangan rusun Dinas perumahan permukiman } \\
\text { rakyat dan cipta karya provinsi Jawa Timur }\end{array}$ \\
\hline & - & $\begin{array}{l}\text { Pengelola lokasi merupakan pihak ketiga yang diberi } \\
\text { tugas oleh Dinas untuk membantu mengelola rusunawa } \\
\text { dalam hal administrasi penghunian, kebersihan dan } \\
\text { keamanan }\end{array}$ \\
\hline Struktur Organisasi & - & $\begin{array}{l}\text { Struktur organisasi cukup efektif, rantai koordinasi tidak } \\
\text { panjang }\end{array}$ \\
\hline Hubungan dengan stake holder lain & - & $\begin{array}{l}\text { Pengelolaan rusunawa tidak melibatkan stake holder atau } \\
\text { Dinas lain yang terkait }\end{array}$ \\
\hline Sumber Dana & - & $\begin{array}{l}\text { Sumber dana pengelolaan berasal dari DIPA Dinas } \\
\text { (APBD Provinsi Jawa Timur) }\end{array}$ \\
\hline Penganggaran & - & $\begin{array}{l}\text { Penyusunan anggaran pengelolaan rusunawa dilakukan } \\
\text { setiap tahun }\end{array}$ \\
\hline Manjemen keuangan & - & $\begin{array}{l}\text { Penerimaan biaya sewa unit hunian rusunawa langsung } \\
\text { diserahkan ke kas daerah, tidak bisa langsung digunakan } \\
\text { sebagai biaya pengelolaan }\end{array}$ \\
\hline \multirow[t]{2}{*}{ Jumlah SDM } & - & $\begin{array}{l}\text { Jumlah SDM pengelola di lokasi berjumlah } 10 \text { orang, } \\
\text { terdiri dari } 3 \text { administrasi, } 5 \text { keamanan, } 3 \text { kebersihan }\end{array}$ \\
\hline & - & $\begin{array}{l}\text { Jumlah tenaga kebersihan masih kurang bila } \\
\text { dibandingkan dengan area rusunawa yang harus } \\
\text { dibersihkan }\end{array}$ \\
\hline Hari Kerja & - & Senin-Jumat, mulai pukul $09.00-16.30$ \\
\hline \multirow[t]{2}{*}{ Kompetensi SDM } & - & $\begin{array}{l}\text { SDM pengelola rusunawa pernah mengikuti pelatihan } \\
\text { tentang pengelolaan rusunawa }\end{array}$ \\
\hline & - & $\begin{array}{l}\text { Kompetensi SDM pengelola memadai akan tetapi } \\
\text { aplikasi di lapangan tidak maksimal karena belum ada } \\
\text { SOP atau panduan pengelolaan sehingga pengelolaan } \\
\text { rusunawa tidak maksimal }\end{array}$ \\
\hline $\begin{array}{l}\text { Motto pelayanan/budaya yang dibangun dalam } \\
\text { organisasi pengelola }\end{array}$ & - & $\begin{array}{l}\text { Tidak ada motto pelayanan maupun budaya yang sengaja } \\
\text { dibangun oleh pengelola rusunawa dalam rangka } \\
\text { peningkatan kualitas pelayanan rusunawa. }\end{array}$ \\
\hline
\end{tabular}




\section{Lanjutan Tabel 4}

\begin{tabular}{|c|c|c|}
\hline $\begin{array}{l}\text { Motto pelayanan/budaya yang dibangun dalam } \\
\text { organisasi pengelola }\end{array}$ & - & $\begin{array}{l}\text { Tidak ada motto pelayanan maupun budaya yang sengaja } \\
\text { dibangun oleh pengelola rusunawa dalam rangka } \\
\text { peningkatan kualitas pelayanan rusunawa. }\end{array}$ \\
\hline \multirow[t]{8}{*}{ Kualitas Rusunawa yang berada di kuadran I } & - & $\begin{array}{l}\text { Sarana pembuangan air limbah/kotor tidak berfungsi } \\
\text { dengan baik }\end{array}$ \\
\hline & - & Fasilitas jemur pakaian kurang memadai \\
\hline & - & $\begin{array}{l}\text { Pengelolaan sampah terutama frekuensi pengangkutan } \\
\text { sampah dari TPS ke TPA kurang }\end{array}$ \\
\hline & - & Kualitas perbaikan sarana, prasarana, dan utilitas kurang \\
\hline & - & $\begin{array}{l}\text { Pekerjaan pemeliharaan dan pemeriksaan berkala pada } \\
\text { komponen bangunan jarang dilakukan }\end{array}$ \\
\hline & - & Pekerjaan perawatan bangunan masih kurang \\
\hline & - & $\begin{array}{l}\text { Kecukupan SDM Pengelola, dalam hal kurangnya jumlah } \\
\text { petugas kebersihan }\end{array}$ \\
\hline & - & $\begin{array}{l}\text { Respon pengelola terhadap keluhan penghuni kurang } \\
\text { cepat }\end{array}$ \\
\hline
\end{tabular}

Tabel 5. Rekomendasi pengelolaan Rusunawa Gunungsari

Variabel 7s Mc Rekomendasi Pengelolaan
Kinsey

\begin{tabular}{ll}
\hline Kebijakan/ 1. & $\begin{array}{l}\text { Pengelola perlu membuat kebijakan untuk segera menyusunSOP pemeliharaan dan } \\
\text { perawatan }\end{array}$ \\
Strategi &
\end{tabular}

2. Pengelola perlu mencari alternatf tempat jemur pakaian bagi penghuni atau mengubah desain teralis dibagian tempat jemuran di masing-masing unit hunian, sehingga pakaian cepat kering

3. Melibatkan warga dalam pengelolaan sampah, seperti memilah sampah, dan membuang sampah pada shaft sampah yang telah disediakan.

4. Menerapkan tata tertib penghuni dengan tegas, terutama soal kebersihan/membuang sampah sembarangan.

5. Bekerja sama dengan Pemerintah Kota Surabaya dalam rangka pengangkutan sampah dari TPS rusunawa ke TPA, agar timbulan sampah di rusunawa dapat diangkut secara rutin.

6. Pengelola rusunawa dalam hal ini adalah Dinas Perumahan Kawasan Permukiman dan Cipta Karya sebaiknya mempunyai tenggat waktu dalam merespon keluhan penghuni, terutama terkait dengan perbaikan sarana, prasarana, dan utilitas yang telah dibuat sehingga kegiatan-kegiatan periodik yang perlu dilakukan dapat terlaksana dengan baik dan sesuai rencana, seperti setiap berapa bulan menguras bak septitank, pengecekan saluran air limbah, dan sebagainya. 
Lanjutan Tabel 5

\begin{tabular}{lrl}
\hline $\begin{array}{l}\text { Variabel 7s Mc } \\
\text { Kinsey }\end{array}$ & Rekomendasi Pengelolaan \\
\hline Sistem/Regulasi & 2. & $\begin{array}{l}\text { Evaluasi rusunawa tidak hanya tentang kepenghunian dan keuangan, akan tetapi juga } \\
\text { menyangkut sarana, prasarana, dan utilitas, hasil dari evaluasi ini dapat disusun prioritas } \\
\text { perbaikan yang dapat digunakan sebagai sarana untuk penentuan anggaran pemeliharaan } \\
\text { dan perawatan. }\end{array}$ \\
& 3. & Menambah anggaran untuk biaya pegawai, untuk biaya pegawai kebersihan. \\
\hline Anggaran & 4. & $\begin{array}{l}\text { Menganggarkan biaya pemeliharaan dan perawatan sesuai dengan hasil evaluasi sarana, } \\
\text { prasarana, dan utilitas }\end{array}$ \\
/Pembiayaan & 2. & $\begin{array}{l}\text { Menambah tenaga kebersihan. } \\
\text { Sumber Daya }\end{array}$ \\
Manusia & 3. & $\begin{array}{l}\text { Menekankan budaya kebersihan dan kerapian, agar tujuan rusunawa untuk mengurangi } \\
\text { kekumuhan, bukan memindahkan kekumuhan horizontal ke kekumuhan vertical dapat } \\
\text { tercapai. }\end{array}$ \\
\hline Budaya & $\begin{array}{l}\text { Menekankan bahwa pemeliharaan sangat penting dilakukan untuk menekan kerusakan } \\
\text { yang menyebabkan mahalnya biaya perbaikan. }\end{array}$ \\
\hline
\end{tabular}

\section{KESIMPULAN}

Berdasarkan analisis yang dilakukan dalam penelitian ini maka diperoleh kesimpulan sebagai berikut :

1. Perbandingan antara persepsi dan harapan penghuni (tingkat kesesuaian total) Rusunawa Gunung Sari adalah sebesar $74.18 \%$.

2. Kondisi organisasi yang berkontribusi terhadap kualitas pelayanan rusunawa yang ada di kuadran I sesuai dengan variabel 7s Mc Kinsey adalah pada variabel strategi yaitu tidak adanya kebijakan pengelola terkait dengan pemeliharaan dan perawatan rusunawa, variabel sistem/regulasi yaitu tidak adanya SOP pemeliharaan dan perawatan, dan kurangnya penegakan tata tertib penghuni, variabel anggaran dan pembiayaan yaitu kurangnya anggaran pemeliharaan dan perawatan rusunawa, serta variabel SDM yaitu kurangnya jumlah tenaga kebersihan.

3. Rekomendasi pengelolaan rusunawa untuk meningkatkan kinerja pelayanan yang berada di kuadran I yang dapat dilakukan oleh pengelola yaitu pengelola perlu menyusun dan melaksanakan SOP pemeliharaan dan perawatan rusunawa, menegakkan tata tertib hunian dengan baik, melakukan evaluasi pengelolaan rusunawa secara menyeluruh sehingga dapat dijadikan acuan penganggaran tahun berikutnya terutama untuk perawatan dan pemeliharaan, dan menambah jumlah tenaga kebersihan

\section{DAFTAR PUSTAKA}

[1] Kementrian Negara Perumahan Rakyat, Peraturan Menteri Negara Perumahan Rakyat No. 14 Tahun 2007 Tentang Pengelolaan Rumah Susun Sederhana Sewa.
20 Tahun 2011 Tentang Rumah Susun.

[3] Berry, LL, Zeithaml, V.A and Parasuraman, 1985. A."Quality Counts in Service too". Business Horizons.Vol.8.No.3.

[4] Schiffman, Leon. G and Kanuk, Leslie Lazar.2004.Consumer Behavior $8^{\text {th }}$ edition. Pearson Prentice Hall.

[5] Aziabah, Samson. Gruis, Vincent. Elsinga, Marja. Van der Flier, Kees. 2015. "Digging Deeper : Public Housing in Ghana Managed by Local Authorities". Social Housing and Globalisation.

[6] Setiadi, A. Harri. 2014. "Persepsi Tingkat Kepuasan Penghuni Terhadap Atribut Rumah Susun Sewa Kemayoran". Jurnal Sosek Pekerjaan Umum, Vol. 6 No.1.

[7] Setiadi, A. Harri. 2015. "Analisis Faktor Berpengaruh Terhadap Kepuasan Penghuni Rumah Susun Sewa Studi Kasus Rumah Susun Kemayoran". Jurnal Permukiman Vol. 10 No.1.

[8] Setabasri01.blogspot.com/2011/04/analisisdeskriptif-dengan-importance.html.Analisis Kuadran Harapan dan Persepsi Publik.

[9] Mahomed, A. M. 2004. "An Analysis of The Johannesburg Regional Office of the Government Communication and Information System using The Mc Kinsey 7s Framework". Disertation. Faculty of Economic and Management Sciences. Demontford University. South Africa.

[10] Pemerintah Provinsi Jawa Timur, Peraturan Gubernur Jawa Timur No. 36 Tahun 2011 Tentang Pengelolaan Rumah Susun Sederhana Sewa Pemerintah Provinsi Jawa Timur. 